

(RESEARCH ARTiClE)

\title{
Risk factors identification of speech and language delay in children in a tertiary level hospital: A pilot study
}

\author{
Fouzia Hoque *, Shaheen Akhter and Muzharul Mannan \\ Institute of Paediatric Neurodisorder and Autism (IPNA), Bangabandhu Sheikh Mujib Medical University, Dhaka, \\ Bangladesh.
}

World Journal of Advanced Research and Reviews, 2021, 11(01), 103-112

Publication history: Received on 10 June 2021; revised on 13 July 2021; accepted on 15 July 2021

Article DOI: https://doi.org/10.30574/wjarr.2021.11.1.0323

\begin{abstract}
Difficulties in the development of speech and language in children are considered as a common paediatric disability and it may have long-lasting effects on social skills, behavior, emotion, education and employment. There are several factors associated with speech and language delay in children which are very crucial to identify for raising awareness among parents as well as for the professional to provide early intervention by looking into them. The aim of this study is to identify risk factors of speech and language delay in children less than 6 years of age within the period of one year in a tertiary level hospital of Bangladesh. A cross-sectional study conducted with 150 children with primary speech and language delay and their parents who attended for speech and language therapy at Outdoor Patient (OPD) of Institute for Paediatric Neurodisorder and Autism (IPNA) in Bangabandhu Sheikh Mujib Medical University (BSMMU) for one year of period. This study found that the aspects being male gender, parental age, use of electronic devices, gestational age at birth, low birth weight and child's attention problem are most common risk factors of speech and language delay in children. These findings help to monitoring the children who have these risk factors and that should draw the attention for early screening, assessment and intervention.
\end{abstract}

Keywords: Risk factors; Speech and language delay; Tertiary level hospital

\section{Introduction}

Speech and language delay in children aged 2 to 5 years old is communal with a probable prevalence between 2 percent and 12 percent. A speech and language delay define that the child is developing his/her speech and language in the correct sequence but at a slower rate than expected [1]. Child is diagnosed as speech delay or language delay when his/her speech is delayed or unintelligible than would be expected for his or her age or is characterized by speech sound error patterns not appropriate for his/her age [2]. The consequences of speech and language delay are many including delayed phonation, childhood stuttering, articulation problem, developmental verbal dyspraxia, unusual voice quality and so on. The children with speech delay need to be diagnosed early as well as intervened into early, because frequently it is seen to be associated with poor intelligence and affected children are at high risk of later academic, behavioral, social difficulties and emotional difficulties[3].There are several factors associated with speech delay including gender, prematurity, low birth weight, inadequate sleep, low income and low parental education, electronics device ,lack of prenatal communication with child, poor nutrition ,relatives marriage, positive family history , nuclear family in urban area etc [4]. To be aware about the risk factors in children aged less than 6 years old with changes in speech-language development as well as implementing early intervention will decrease the impact on various sectors of their life [5].So, this particular study was designed to identify the risk factors of children with speech delay less than six years of age in a tertiary level of hospital which might be helpful for raising awareness among parents of children as well as for the professional to provide early intervention by looking into the possible risk factors.

\footnotetext{
* Corresponding author: Fouzia Hoque

Institute of Paediatric Neurodisorder and Autism (IPNA), Bangabandhu Sheikh Mujib Medical University, Dhaka, Bangladesh.
} 
The objective of the study is to identify the risk factors of speech and language delay in children less than 6 years of age within the period of one year in a tertiary level hospital.

\section{Material and methods}

A cross-sectional study was conducted with 150 children with speech and language delay and their parents who attended for speech and language therapy at Outpatient Department (OPD) of Institute for Paediatric Neurodisorder and Autism (IPNA) in Bangabandhu Sheikh Mujib Medical University (BSMMU) from May 2018 to May 2019 and all of the parents/people in charge of the children signed the informed consent. The sample was selected by using purposive sampling. The inclusion criteria for selecting sample were the children with speech and language delay under 6 years of age. The children more than 6 years of age and having speech and language delay related to neurodevelopment disability were excluded from the study.

A semi-structured questionnaire was used to identify risk factors of children with speech and language delay. The questionnaire was developed by the authors specifically for this research, based on previous studies concerning the risk factors for communication, speech and language delay. Questionnaire for Risk Factors of Speech and Language Delay (QRSLD) (Appendix-1) is a form with 20 items. The parents/responsible parties of children who attended at screening were asked to answer the (QRSLD) form, individually.

Data were tabulated and analyzed using SPSS statistical software version 19, using $\chi 2$ test for association of speech and language delay with variables and descriptive analysis. P-value of 0.05 as considered significant.

\section{Results}

Table 1 The frequency of children with speech and language delay

\begin{tabular}{|l|c|c|}
\hline Speech and Language Delay & Frequency & Percentage (\%) \\
\hline Speech and language delay & 111 & $74 \%$ \\
\hline Childhood stuttering & 24 & $16 \%$ \\
\hline Speech delay with hearing problem & 15 & $10 \%$ \\
\hline Total & 150 & $100 \%$ \\
\hline
\end{tabular}

A total number of 150 children attended to OPD IPNA, BSMMU reporting speech and language delay participated in this study. Children with childhood stuttering $(n=24,16 \%)$ and speech delay with hearing impairment $(n=15,10 \%)$ excluded from this study. So, the final participants were $74 \%(n=111)$ children with speech and language delay (Table=1)

Table 2 Age distribution of children with speech and language delay

\begin{tabular}{|l|c|c|}
\hline Child age & Frequency & Percentage (\%) \\
\hline $0-2$ years & 25 & $22 \%$ \\
\hline $2-4$ years & 62 & $55 \%$ \\
\hline 4-6 years & 24 & $21 \%$ \\
\hline Total & 111 & $100 \%$ \\
\hline
\end{tabular}

Table 3 Distribution of information provider

\begin{tabular}{|l|c|c|}
\hline Information provider & Frequency & Percentage (\%) \\
\hline Mother & 96 & $86.5 \%$ \\
\hline Father & 10 & $9.0 \%$ \\
\hline Others & 5 & $4.5 \%$ \\
\hline Total & 111 & $100 \%$ \\
\hline
\end{tabular}


$($ Table $=2)$ The study classified the age of children with speech and language delay into three categories: 0-2 years ( $\mathrm{n}=25$, $22 \%), 2-4$ years $(n=62,55 \%)$ and $4-6$ years $(n=24,21 \%)$. The majority number of information provider was mother ( $\mathrm{n}=96,86.5 \%)$ shown in Table 3.

Table 4 Gender distribution of children with speech and language delay

\begin{tabular}{|l|c|c|c|}
\hline \multicolumn{1}{|c|}{ Gender } & Frequency & Percentage (\%) & $\boldsymbol{p}$-value \\
\hline Male & 76 & $68.5 \%$ & \\
\hline Female & 35 & $31.5 \%$ & 0.022 \\
\hline Total & 111 & $100 \%$ & \\
\hline
\end{tabular}

Gender distribution listed in Table 4. The number of speech and language delay found more in male ( $\mathrm{n}=76,68.5 \%)$.The association between sex and speech delay was significant ( $p$-value=0.022). Male gender considered as risk factor for speech and language delay shown in Table 4.

Table 5 Distribution of living place of children with speech and language delay

\begin{tabular}{|l|c|c|c|}
\hline \multicolumn{1}{|c|}{ Area } & Frequency & Percentage (\%) & $\boldsymbol{p}$-value \\
\hline Rural & 70 & $63.1 \%$ & \\
\hline Urban & 41 & $36.9 \%$ & 0.318 \\
\hline Total & 111 & $100 \%$ & \\
\hline
\end{tabular}

Table 5 shown that $63.1 \%(n=70)$ participants came from rural area and $36.9 \%(n=41)$ came from urban area. There is no significant relation found of living place with speech and language delay in this study.

Table 6 Distribution of father and mother age on child birth

\begin{tabular}{|c|c|c|c|c|}
\hline Parental age & & Frequency & Percentage & p-value \\
\hline \multirow[t]{5}{*}{ Father } & Under 20 years & 0 & $0 \%$ & \\
\hline & 21-29 years & 17 & $15.3 \%$ & \\
\hline & 30 to 39 years & 61 & $55.0 \%$ & 0.020 \\
\hline & More than 40 years & 33 & $29.7 \%$ & \\
\hline & Total & 111 & $100 \%$ & \\
\hline \multirow[t]{5}{*}{ Mother } & Under 20 years & 15 & $13.5 \%$ & \\
\hline & 21-29 years & 64 & $57.7 \%$ & \\
\hline & 30 to 39 years & 28 & $25.2 \%$ & 0.048 \\
\hline & More than 40 years & 4 & $3.6 \%$ & \\
\hline & Total & 111 & $100 \%$ & \\
\hline \multicolumn{5}{|l|}{ Age of parents } \\
\hline & Normal range & 63 & $56.8 \%$ & \\
\hline & Under 20 or over 40 years & 48 & $43.2 \%$ & 0.014 \\
\hline & Total & 111 & $100 \%$ & \\
\hline
\end{tabular}


The age of child's father and mother were at high risk for speech and language delay in children. Table 6 showed the association of father's age ( $p$-value 0.020 ) and mother's age ( $p$-value 0.048$)$ separately with speech and language delay. The estimate of parental age together under 20 or over 40 years old found $43.2 \%(n=48)$ which shown more significant ( $p$-value 0.014 ).Under 20 years old or over 40 years old, both are considered as a risk factors for children with speech and language delay. Distribution of parental literacy level shown in Table 7, there were no association between father ( $p$-value 0.263$)$ and mother ( $p$-value 0.186$)$ literacy level with speech delay children (Table 7).

Table 7 Distribution of parental education level

\begin{tabular}{|l|l|c|c|c|}
\hline Parental education & & Frequency & Percentage & $\boldsymbol{p}$-value \\
\hline Father & Illiterate & 15 & $13.5 \%$ & \\
\hline & Primary & 15 & $13.5 \%$ & \\
\hline & Secondary & 15 & $13.5 \%$ & 0.263 \\
\hline & Higher Secondary & 21 & $18.9 \%$ & \\
\hline & Higher degree & 45 & $40.5 \%$ & \\
\hline Mother & Total & 111 & $100 \%$ & \\
\hline & Illiterate & 16 & $14.4 \%$ & \\
\hline & Primary & 13 & $11.7 \%$ & \\
\hline & Secondary & 23 & $20.7 \%$ & 0.186 \\
\hline & Higher Secondary & 23 & $20.7 \%$ & \\
\hline & Higher degree & 36 & $32.4 \%$ & \\
\hline & Total & 111 & $100 \%$ & \\
\hline
\end{tabular}

Table 8 Distribution of types of family and parental socio-economic status

\begin{tabular}{|l|l|c|c|c|}
\hline & & Frequency & Percentage (\%) & $\boldsymbol{p}$-value \\
\hline Family type & Nuclear family & 66 & $59.5 \%$ & \\
\hline & Joint family & 45 & $40.5 \%$ & 0.259 \\
\hline & Total & 111 & $100 \%$ & \\
\hline Socio-economic status & Lower class & 29 & $26.1 \%$ & \\
\hline & Middle class & 59 & $53.2 \%$ & 0.110 \\
\hline & Higher class & 23 & $20.7 \%$ & \\
\hline & Total & 111 & $100 \%$ & \\
\hline
\end{tabular}

Table 8 indicated the distribution of family type of child; nuclear family $(n=66,59.5 \%)$, joint family $(n=45,40.5 \%)$ and parental socio-economic status; lower class $(n=29,26.1 \%)$, middle class $(n=59,53.2 \%)$, higher class $(n=23,20.7 \%)$. Parents of children with speech and language delay participated in this study living in nuclear family $(n=66,59.5 \%)$ more than joint family $(\mathrm{n}=45,40.5 \%)$. There was no association ( $p$-value 0.259$)$ found between speech and language delay with family type of child. No association ( $p$-value 0.110$)$ also found between parental socio-economic status and speech and language delay.

Association of speech and language delay with child's attendant in home was not significant ( $p$-value 0.256).74.8\% mother $(n=83)$ took care of their children in home. 39.6\% parents didn't communicate with their child properly in home and significant level ( $p$-value 0.120) shown in Table 9. 
Table 9 Distribution of attendant of child in home and parental communication with parents

\begin{tabular}{|l|l|c|c|c|}
\hline & & Frequency (n) & Percentage (\%) & p-value \\
\hline Attendant of child & Mother & 83 & $74.8 \%$ & \\
\hline & Grandparents & 13 & $11.7 \%$ & \\
\hline & Maid & 9 & $8.1 \%$ & 0.256 \\
\hline & Others & 6 & $5.4 \%$ & \\
\hline \multirow{2}{*}{ Parent-child interaction } & Total & 111 & $100 \%$ & \\
\hline & No & 67 & $60.4 \%$ & \\
\hline & Notal & 44 & $39.6 \%$ & 0.120 \\
\hline
\end{tabular}

Table 10 Distribution of the number of positive family history, history of consanguineous marriage in family and number of language use in home

\begin{tabular}{|l|l|c|c|c|}
\hline & & Frequency (n) & Percentage (\%) & $\boldsymbol{p}$-value \\
\hline Positive family history & No & 59 & $53.2 \%$ & \\
\hline & Parents & 15 & $13.5 \%$ & \\
\hline & Siblings & 9 & $8.1 \%$ & 0.078 \\
\hline & Others & 28 & $25.2 \%$ & \\
\hline Consanguineous marriage & Total & 111 & $100 \%$ & \\
\hline & Yes & 10 & $9 \%$ & \\
\hline & No & 101 & $91 \%$ & 0.252 \\
\hline Use of different language & Total & 111 & $100 \%$ & \\
\hline & No & 78 & $70.3 \%$ & \\
\hline & English & 26 & $23.4 \%$ & \\
\hline & Others & 7 & $6.3 \%$ & 0.280 \\
\hline & Total & 111 & $100 \%$ & \\
\hline
\end{tabular}

Table 10 showed the distribution of family history, consanguineous marriage and number of language used in home environment. No significant association found between speech and language delay with all of them. Positive family history showed significant level ( $p$-value 0.078 ) which were $13.5 \%$ related to parental history $(\mathrm{n}=15)$ of speech and language delay, $8.1 \%$ with siblings $(n=9)$ and $25.2 \%$ with other family members.9\% parental marriage was consanguineous marriage ( $p$-value 0.252 ). $70.3 \%$ family members used only Bangla language in home with child $(p$ value 0.280 ) and $23.4 \%$ used English and $6.3 \%$ used other language mixed with Bangla.

The use of electronic devices like mobile, TV and others showed significant association with speech and language delay ( $p$-value 0.043$)$. Mobile was extremely used by $51.4 \%$ children $(n=57)$ under age of 6 and $10.8 \%$ children $(n=12)$ was addicted to watch TV .Parental complaining of attention problem in child also showed the significant association $(p$ value 0.053 ) with speech and language delay.29.7\% complained that their child didn't sleep enough which didn't consider as a risk factor of speech delay and its significant level was ( $p$-value 0.301). 
Table 11 Distribution of using electronic device in home by child, parental complain of child attention problem and less sleeping

\begin{tabular}{|l|l|c|c|c|}
\hline & & Frequency (n) & Percentage (\%) & $\boldsymbol{p}$-value \\
\hline Use of electronic devices & No & 38 & $34.2 \%$ & \\
\hline & Mobile & 57 & $51.4 \%$ & \\
\hline & TV & 12 & $10.8 \%$ & 0.043 \\
\hline & Others & 4 & $3.6 \%$ & \\
\hline Attention problem of child & Yes & 49 & $100 \%$ & \\
\hline & No & 62 & $54.1 \%$ & \\
\hline & Total & 111 & $100 \%$ & \\
\hline Less sleeping & Yes & 33 & $29.7 \%$ & \\
\hline & No & 78 & $70.3 \%$ & 0.3053 \\
\hline & Total & 111 & $100 \%$ & \\
\hline
\end{tabular}

Table 12 Distribution of birth history, low birth weight and nutritional status of child

\begin{tabular}{|l|l|c|c|c|}
\hline & & Frequency (n) & Percentage (\%) & p-value \\
\hline Gestational age at birth & Normal & 58 & $52.3 \%$ & \\
\hline & Pre-maturity & 41 & $36.9 \%$ & \\
\hline & Post-maturity & 12 & $10.8 \%$ & 0.041 \\
\hline Low Birth Weight & Total & 111 & $100 \%$ & \\
\hline & Normal & 61 & $55 \%$ & \\
\hline & Low birth weight & 44 & $39.6 \%$ & \\
\hline & Very low birth weight & 6 & $5.4 \%$ & 0.054 \\
\hline Poor nutrition & Total & 111 & $100 \%$ & \\
\hline & Yes & 73 & $65.8 \%$ & \\
\hline & No & 38 & $34.2 \%$ & 0.078 \\
\hline & Total & 111 & $100 \%$ & \\
\hline
\end{tabular}

Distribution of birth history, low birth weight and poor nutrition are illustrated in table 12 . Birth history were categorized into 3 parts; normal birth history $(n=58,52.3 \%)$, history of pre-maturity ( $n=41,36.9 \%)$, history of postmaturity $(n=12,10.8 \%)$ and birth weight were also divided into 3 category; normal birth weight (n=61, 55\%), history of low birth weight $(n=44,39.6 \%)$, history of high birth weight $(n=6,5.4 \%)$.Birth history and birth weight were considered as risk factors for speech delay because the association between speech and language delay with birth history was significant ( $p$-value 0.041 ) as well as birth weight also showed significant association ( $p$-value 0.054) with speech and language delay.65.8\% children $(n=73)$ with poor nutrition attended this study and there was no significant association ( $p$-value 0.078 ) found between poor nutrition with speech and language delay.

\section{Discussion}

We first targeted to establish the pre-existing risk factors which are significantly associated with primary speech and language delay in children under 6 years of age and to find out the most common risk factors among these. The most common variables identified as risk factors were; male gender, parental age, and use of electronic devices, gestational 
age at birth, low birth weight and child's attention problem. There are wide-ranging studies on speech and language delay available in western literature but there are lacks of similar data in Bangladesh.

Table 13 Questionnaire for Risk Factors of Speech and Language Delay (QRSLD)

\begin{tabular}{|c|l|}
\hline Sr. no. & Questionnaire \\
\hline 1 & $\begin{array}{l}\text { Complaint of sppech and language } \\
\text { age problem }\end{array}$ \\
\hline 2 & Age \\
\hline 3 & Information provider \\
\hline 4 & Gender \\
\hline 5 & Area of living \\
\hline 6 & Parental age \\
\hline 7 & Parental education \\
\hline 8 & Family type \\
\hline 9 & Socio-economic status \\
\hline 10 & Attendant of child at home \\
\hline 11 & Parent-child interaction \\
\hline 12 & Positive family history \\
\hline 13 & Consanguineous marriage \\
\hline 14 & Different language use in home \\
\hline 15 & Use of electronic device \\
\hline 16 & Attention problem of child \\
\hline 19 & Less sleeping \\
\hline 20 & Gestational age of birth \\
\hline & Low birth weight \\
\hline 19 & Poor nutrition \\
\hline 13 & \\
\hline 13 & \\
\hline 13 &
\end{tabular}

However, in our study 86.5\% informer were mother and maximum speech and language delay occurred in two to four years of age .A recent study on risk factors of speech-language problem in children has found the predominant age group of the participating children with speech delay was between 2 and 5 years of age [6]. Another study found the average age of children with speech and language delay at diagnosis was 3 years 10 months [7].A study done in Bangladesh also showed the majority of children with speech delay were 2 to 4 years of age [3]. Several study found the association of speech-language delay with gender was significant and male was risk factor of delay [4,8-13]. In this investigation, most of the participants were male (68.5\%) which is almost similar to the study done one author which showed $69.4 \%$ male participants [5].This finding are also corroborating with other national and international literature. The fact of being male was considered as an important risk factor and the family with a positive history of unclear speech, stuttering, late speaking and poor vocabulary, had nearly more possibilities to have a child with primary speech and language delay according to different investigators [4,8] . But our study didn't show any significant association as p-value was $0.078(P$ value $>0.05$ ) between positive family history with primary speech and language delay. It may tend to increase if sample size increased. Older maternal age at birth is a risk factor for speech and language delay in children [14]. Another study reported that the age of the parents is considered as risk factors for speech and language delay in children [5].Our study also supporting this statement and significant relationship ( $p$-value 0.014 ) found between parental age and speech and language delay in children. Though several authors stated that there is an effect of low parental education on speech development $[12,15,16]$, but one other study didn't find any significant association between the level of paternal or maternal education and specific language impairment [19].Poor SES is a risk factor for primary speech and language delay in children reported by many authors $[5,12,15,18]$, which is disagreed by Choudhury et al [17]. Our study failed to 
show an association between speech and language delay with parental education and low SES which is similar to a study done by Kumar [19].

A study depicted that language problems typically co-occurred with problems of attention in children [20]. Previous studies also observed the co-occurrence of intentional difficulties with speech and language impairment but the nature of relationship was unclear in a study done by Redmond et al [21]. According to Hammer et al, attention problem in children is a risk factor for children with speech and language delay. Our study found a significant association as $p$-value was 0.053 (P value $>0.05$ ) between intentional problem with primary speech and language delay in children. Our study didn't find disturbance in sleep can causes speech and language difficulties in children which contradict with some study. That study showed this is evident that children with sleep disorders are at risk for speech and language problems $[24,25]$.

Some studies demonstrated that there is a strong association of using electronic devices with development of speech and language delay [3,26,30-32]. This finding is also supported by our study. We considered that using electronic devices is risk factors for primary speech and language delay as $p$-value found (0.043). No statistical association also found with primary speech and language delay with children with malnutrition ( $p$-value 0.078)

This study found that gestational age and child birth weight during birth has a strong association with speech and language delay in children. Some studies showed that prematurity [33], low birth weight [11] and very low birth weight [35] were significant risk factors for speech impairment [27,28,35-39,40,41]. In contrast, another study demonstrated no significant association of speech delay with low birth weight and higher birth order [8]. According to Smithers et al, early term or post-term gestational age at birth may explain the higher risk of vulnerability on the Language skills domain compared with other domains [42].

Our findings contradict with few studies that found parent-child interaction has an influence on delayed speech and language development of child [3,29].Our study also demonstrated that $25.2 \%$ children with speech and language delay had attended by grandmother, maid and other relatives in home as $p$-value found (0.256) as well as $29.7 \%$ family used more than one language in home. One literature [29] depicted that consanguineous marriage has a little effect on speech and language delay but our study didn't support that statement. We didn't find any association of consanguineous marriage with primary speech and language delay. Children living in the type of family and primary speech and language delay were not found to be statistically significant as $p$-value was $(0.259)$ as against some studies $[6,20]$. we didn't find significant association of speech and language delay with child's area of living [7].

\section{Conclusion}

Speech and language development is an useful indicator of child's overall development. Data from our study suggests that the aspects being male gender, parental age, and use of electronic devices, gestational age at birth, low birth weight and child's attention problem considered as most common risk factors of speech and language delay in children. This study helps to exclude the common and associated risk factors which is responsible for speech and language delay in our country context, also helps to increase awareness and consciousness among parents about their child. These results thus justify the need for monitoring of children who have these risk factors, early screening and assessment of child's developmental milestones and implementation of intervention.

\section{Compliance with ethical standards}

\section{Acknowledgments}

The authors gratefully acknowledge the Institute for Paediatric Neurodisorder and Autism (IPNA), Bangabandhu Sheikh Mujib Medical University (BSMMU) for supporting this work.

\section{Disclosure of conflict of interest}

The authors declare that there is no conflict of interests regarding the publication of this paper.

\section{Statement of informed consent}

Informed consent was obtained from all individual participants included in the study. 


\section{References}

[1] Law J, Boyle J, Harris F, Harkness A, Nye C. Prevalence and natural history of primary speech and language delay: findings from a systematic review of the literature. Int J Lang Commun Disord. 2000; 35(2): 165-188.

[2] Shriberg LD, Austin D, Lewis BA, McSweeny JL, Wilson DL. The Speech Disorders Classification System (SDCS): Extensions and lifespan reference data, Journal of Speech, Language, and Hearing Research. 1997; 40: 723-40.

[3] Tanjina Sharifa, Wahida Khanam, Zahid Hassan Arefin M, KaziIstiaque Sanin. Risk factors of speech delay in otherwise normal under-five children: a case-control study, International Journal of Development Research. 2018; 8(11): 23967-23973.

[4] Mondal N, Bhat B, Plakkal N, Thulasingam M, Ajayan P, et al. Prevalence and Risk Factors of Speech and Language Delay in Children Less Than Three Years of Age, J Compr Ped. 2016; 7(2): e33173.

[5] Silva, Gabriela Martins Duarte, Couto, Maria Ines Vieira, Molini-Avejonas, Daniela Regina. Risk factors identification in children with speech disorders: pilot study. CoDAS. 2013; 25(5): 456-462.

[6] Regina D, et al. Risk Factors for Speech-Language Pathologies in Children, Advances in Speech-language Pathology'; Dr. Fernanda Fernandes (Ed.), InTech. 2017.

[7] Christine E, E Delgado, Sara J, Vagi, Keith G Scott. 'Early Risk Factors for Speech and Language Impairments', Exceptionality; 13(3), 173-19, Copyright (C2005, Lawrence Erlbaurn Associates. 2005.

[8] Saeed HT, Abdulaziz B, AL-Daboon SJ. Prevalence and Risk Factors of Primary Speech and Language Delay in Children Less than Seven Years of Age. J Community Med Health Educ. 2018; 8: 608.

[9] Nelson HD, Nygren P, Walker M, Panoscha R. Screening for speech and language delay in preschool children: systematic evidence review for the US Preventive Services Task Force. Pediatrics. 2006; 117(2): -319.

[10] Binu A, Sunil R, Baburaj S, Mohandas MK. Sociodemographic profile of speech and language delay up to six years of age in Indian children. Int J Med Res Health Sci. 2014; 3(1): 98.

[11] Karbasi SA, Fallah R, Golestan M. The prevalence of speech disorder in primary school students in Yazd-Iran. Acta Med Iran. 2011; 49(1): 33-7.

[12] Campbell TF, Dollaghan CA, Rockette HE, Paradise JL, Feldman HM, Shriberg LD, et al. Risk factors for speech delay of unknown origin in 3-year-old children. Child Dev. 2003; 74(2): 346-57.

[13] Harrison LJ, McLeod S. Risk and protective factors associated with speech and language impairment in a nationally representative sample of 4- to 5-year-old children. Journal of Speech, Language, and Hearing Research. 2010; 53: 508-529.

[14] Hammer CS, Morgan P, Farkas G, Hillemeier M, Bitetti D, Maczuga S. Late Talkers: A Population-Based Study of Risk Factors and School Readiness Consequences. Journal of speech, language, and hearing research: JSLHR. 2017; 60(3): 607-626.

[15] Sidhu M, Malhi P, Jerath J. Early language development in Indian children: A population-based pilot study. Ann Indian Acad Neurol. 2013; 16(3): 371-5.

[16] Stanton-Chapman TL, Chapman DA, Bainbridge NL, Scott KG. Identification of early risk factors for language impairment. Res Dev Disabil. 2002; 23(6): 390-405.

[17] Choudhury N, Benasich AA. A family aggregation study: the influence of family history and other risk factors on language development. J Speech Lang Hear Res. 2003; 46(2): 261-72.

[18] Singer LT, Siegel AC, Lewis B, Hawkins S, Yamashita T, Baley J. Preschool language outcomes of children with history of bronchopulmonary dysplasia and very low birth weight. J Dev Behav Pediatr. 2001; 22(1): 19-26.

[19] Kumar B. Study of Factors Attributing To Language and Speech Delay for Early Detection and Intervention in High Risk Children. 2016.

[20] McGregor KK, Alper RM. Sleep Disorders as a Risk to Language Learning and Use. EBP briefs. 2015; 10(1): 1-21.

[21] Redmond SM, Hogan T, Ash A, Guarino A. Language and attention contributions to the acquisition of decoding skills: Evidence for divergent pathways in children with and without language impairment. Poster presented at the 13th International Congress for the Study of Child Language, Amsterdam, the Netherlands. 2014. 
[22] Karen Bonuck, Roy Grant. Sleep Problems and Early Developmental Delay: Implications for Early Intervention Programs. Intellectual and Developmental Disabilities. February 2012; 50(1): 41-52.

[23] Chonchaiya W, Pruksananonda C. Television viewing associates with delayed language development. Acta Paediatrica. 2008; 97: 977-982.

[24] Linebarger DL, Walker D. Infants' and toddlers' television viewing and language outcomes. The American Behavioral Scientist. 2005; 48: 624-645.

[25] Ruangdaraganon N, Chuthapisith J, Mo-suwan L, et al. BMC Pediatr. 2009; 9: 34.

[26] Van den Heuvel M, Ma J, Borkhoff CM, Koroshegyi C, Dai D, Parkin PC. TARGet Kids! Collaboration (2018). Mobile Media Device Use is Associated with Expressive Language Delay in 18-Month-Old Children. Journal of developmental and behavioral pediatrics : JDBP. 2018; 40(2): 99-104.

[27] Schirmer, Carolina Rizzotto, Portuguez, Mirna Wetters, Nunes, Magda Lahorgue. Clinical assessment of language development in children at age 3 years that were born preterm. Arquivos de Neuro-Psiquiatria. 2006; 64(4): 926931.

[28] Bühler KE, Limongi SC, Diniz EM. Language and cognition in very low birth weight preterm infants with PELCDO application. Arq Neuropsiquiatr. 2009; 67: 242-9.

[29] Christine E, E Delgado, Sara J, Vagi, Keith G Scott. 'Early Risk Factors for Speech and Language Impairments', Exceptionality; 13(3), 173-19, Copyright (C2005, Lawrence Erlbaurn Associates. 2005.

[30] Fitzgerald K, Safley M.'Contributing factors in Children At Risk for Speech/Language Delays';Paper presentation on. 19 November 2009.

[31] Amanda B Zerbeto, Fernando M Cortelo, Élio BC Filho. Association between gestational age and birth weight on the language development of Brazilian children: a systematic review Jornal de Pediatria (Versão em Português). July-August 2015; 91(4): 326-332.

[32] Ribeiro et al. BMC pediatrics 2011, 11:59. Research article, Attention problems and language development in preterm children:cross lagged relations from 18-36 months

[33] Foster-Cohen S, et al. 2007 , August 24 (3) : 665-75 “Early delayed language development in very preterm infants: evidence from the Mac Arthur Bater CDI

[34] Aram DM, Hack M, Hawkins S, Weissman BM, et al. Very-low-birthweight children and speech and language development. Journal of Speech \& Hearing Research. 1991; 34(5): 1169-1179.

[35] Schirmer, Carolina Rizzotto, Portuguez, Mirna Wetters, Nunes, Magda Lahorgue. Clinical assessment of language development in children at age 3 years that were born preterm. Arquivos de Neuro-Psiquiatria. 2006; 64(4): 926931.

[36] Zerbeto Amanda B, Cortelo Fernando M, C Filho, Élio B. Association between gestational age and birth weight on the language development of Brazilian children: a systematic review. Jornal de Pediatria. 2015; 91(4): 326-332.

[37] Da Silva ES, Nunes ML. The influence of gestational age and birth weight in the clinical assessment of the muscle tone of healthy term and preterm newborns. Arq Neuropsiquiatr. 2005; 63: 956-62.

[38] Smithers LG, Searle AK, Chittleborough CR, Scheil WK, Brinkman S, Lynch JW. A whole-of-population study of term and post-term gestational age at birth and children's development. BJOG: an international journal of obstetrics and gynaecology. 2015; 122(10): 1303-11.

[39] Safwat RF, Sheikhany AR. Effect of parent interaction on language development in children. Egypt J Otolaryngol. 2014; 30: 255-63.

[40] Maheswari K, Wadhwa L. Role of consanguinity in paediatric neurological disorders. Int J Contemp Pediatr. 2016; 3: 939-42.

[41] M Frisk, et al. European child and adolescent psychiatry 8:222. A complex background in children and adolescents with psychiatry disorders. Developmental delay, dyslexia, hereditary slow cognitive processing and adverse social factors in a multi factorial entirety. 1999.

[42] Kornilov SA, Lebedeva TV, Zhukova MA, Prikhoda NA, Korotaeva IV, Koposov RA, Grigorenko EL. Language development in rural and urban Russian-speaking children with and without developmental language disorder. Learning and individual differences. 2016; 46: 45-53. 